AperTO - Archivio Istituzionale Open Access dell'Università di Torino

\title{
Malignant pleural mesothelioma in a female Lion (Panthera leo)
}

\section{This is the author's manuscript}

Original Citation:

Availability:

This version is available http://hdl.handle.net/2318/103832

since 2016-01-12T15:44:56Z

Published version:

DOI:10.1016/j.rvsc.2010.08.005

Terms of use:

Open Access

Anyone can freely access the full text of works made available as "Open Access". Works made available under a Creative Commons license can be used according to the terms and conditions of said license. Use of all other works requires consent of the right holder (author or publisher) if not exempted from copyright protection by the applicable law. 


\section{(28) \\ UNIVERSITÀ DEGLI STUDI DI TORINO}

This Accepted Author Manuscript (AAM) is copyrighted and published by Elsevier. It is posted here by agreement between Elsevier and the University of Turin. Changes resulting from the publishing process - such as editing, corrections, structural formatting, and other quality control mechanisms - may not be reflected in this version of the text. The definitive version of the text was subsequently published in Res Vet Sci, 91(1):116-8,2011, doi: 10.1016/j.rvsc.2010.08.005.

You may download, copy and otherwise use the AAM for non-commercial purposes provided that your license is limited by the following restrictions:

(1) You may use this AAM for non-commercial purposes only under the terms of the CC-BY-NC-ND license.

(2) The integrity of the work and identification of the author, copyright owner, and publisher must be preserved in any copy.

(3) You must attribute this AAM in the following format: Creative Commons BY-NC-ND license (http://creativecommons.org/licenses/by-nc-nd/4.0/deed.en), http://dx.doi.org/10.1016/j.rvsc.2010.08.005 


\title{
Malignant pleural mesothelioma in a female Lion (Panthera leo)
}

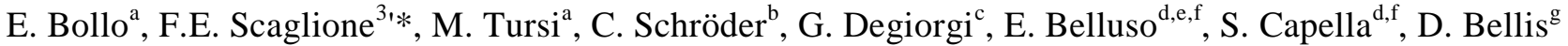

a Dipartimento di Patologia Animale, Università degli Studi di Torino, Via L da Vinci 44, 10095 Grugliasco (TO), Italy
${ }^{b}$ Biologist, Safaripark Pombia, SS $32 \mathrm{Km}$ 23,4, 28050 Pombia (NO), Italy
${ }^{\mathrm{c}}$ Via Selvigia 39, 28040 Varallo Pombia (NO), Italy
${ }^{d}$ Dipartimento di Scienze Mineralogiche e Petrologiche, Università degli Studi di Torino, Via Valperga Caluso 35, 10126 Torino, Italy
${ }^{e}$ Istituto di Geoscienze e Georisorse, CNR-Unità di Torino, Via Valperga Caluso 35, 10125 Torino, Italy
${ }^{f}$ Centro Interdipartimentale per lo Studio degli Amianti e di altri Particolati Nocivi 'Giovanni Scansetti", Università degli Studi di Torino, Via P. Giuria 7, 10125 Torino, Italy
${ }^{g}$ Azienda Sanitaria ASL 4, Servizio di Anatomia ed Istologia Patologica, Ospedale Emergenza Torino Nord San Giovanno Bosco, Piazza del Donatore di Sangue 3,10154 Torino, Italy

Keywords: Asbestos Lion, Mesothelioma Panthera leo

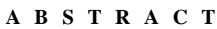

An 18-year-old female lion (Panthera leo) was referred to the Department of Animal Pathology of the University of Turin (Italy). At necropsy, multiple nodular, 4-20-mm, confluent white firm nodules were scattered throughout the pleural surfaces of the thoracic wall and of the lungs. Histological lesions were represented by proliferations of papillary structures lined by cuboidal basophilic mesothelial cells with large, oval nuclei and abundant granular eosinophilic cytoplasm. Immunohistochemistry revealed immu-noreactivity for pancytokeratin and vimentin. None of the cells expressed calretinin antigen. Asbestos fibers and asbestos bodies were not detected respectively by light microscopy and by Scanning Electron Microscope-Energy Dispersive Spectrometer investigations. On the contrary, chrysotile asbestos were identified in samples from shelter material. Histological and immunohistochemical findings were consistent with the diagnosis of an epithelial malignant mesothelioma. To our best knowledge, this is the first report of a pleural mesothelioma in a lion.

Mesotheliomas are malignant tumours that arise from the mesothelial cells of the pleura, peritoneum and pericardium, and occasionally from the tunica vaginalis testis. These tumours are rare in all species but have been recorded most frequently in man, especially in association with exposure to asbestos (McCaughey et al., 1983).

Mesotheliomas in zoo and wild animals appear an infrequent finding at necropsy (Stewart, 1966; Nashiruddallah and Chakr-aborty, 2003) pleural mesotheliomas being described only in tigers (Panthera tigris) (Rao and Acharjyo, 1994; Shin et al., 1998) and in a clouded leopards (Neofelis nebulosa nebulosa) (Cunningham and Dhillon, 1998). Recently a case of pericardial mesothelioma in a 17-year-old Bengal tiger has been reported (Wiedner et al., 2008).

An 18-year-old female lion (Panthera leo) was referred for the necropsy to the Department of Animal Pathology of the University of Turin (Italy) because of sudden death.

The animal lived all her life in a zoological garden in northern Italy, and was housed during the night in a shelter covered by boards made of asbestos fibers and cement (Eternit $\left.{ }^{\circledR}\right)$. During the day the animal had free access to a large open-air enclosure.

At necropsy, multiple, 4-20-mm, confluent white firm nodules were scattered throughout the pleural surfaces of the thoracic wall and of the lungs (Fig. 1). Other findings were represented by enlargement of mesenteric lymph nodes and a solitary, well demarcated hepatic mass of $7-8 \mathrm{~cm}$ in diameter with multiple cysts.

Tissue samples from lung, pleura, mesenteric lymph nodes and liver were fixed in 10\% neutral buffered formalin (pH 7) and paraffin-embedded for histological examination. Sections (4 lm) were cut using a microtome stained with haematoxylin and eosin, and examined by light microscopy.

Histologically, pleural nodules consisted of proliferations of infiltrative papillary structures with a fibrovascular stroma, lined by one layer of cuboidal basophilic cells with large, oval nuclei, and abundant granular eosinophilic cytoplasm. No significant mitotic activity and vascular invasion were observed (Fig. 2). Histological findings of the mesenteric lymph nodes were consistent with a reactive process, whereas the hepatic lesion consisted of a capsulated, multilocular cystic mass lined with well differentiated biliary epithelium resulting in a biliary cystadenoma.

Additional lung sections were collected on poly-L-lysine-coated slides and processed for immunohistochemistry using the standard avidin-biotin-peroxidase complex method and specific antibodies against pancytokeratin MNF116, vimentin and calretinin (Dako, Glostrup, Denmark). Vimentin positivity in epithelial mesothelioma may be useful in distinguishing it from pulmonary adenocarcinoma, which is usually vimentin-negative. Similarly, the positivity of sarcomatous mesotheliomas for broad-spectrum pancytokeratin is useful in distinguishing this subtype from sarcomas, which are usually cytokeratine-negative (Attanoos et al., 2000; Bacci et al., 2006).

The expression of both pancytokeratin and vimentin markers is a constant feature in mesotheliomas, attributable to the origin of mesothelial cells from the mesoderm, which can differentiate into both epithelial and mesenchymal cells (Mutsaers, 2004; Bacci et al., 2006). Calretinin, a calcium-binding protein expressed in feline neural tissues, is regarded as a reliable marker for mesothelioma in human oncology.

As positive controls, bronchial epithelium and mesenchyma from normal lung of a lion, respectively, for pancytokeratin and vimentin, were used.

Immunohistochemical investigation of the pleural nodules revealed strong and diffuse cytoplasmic immunoreactivity for pancytokeratin, and a weak and multifocal reactivity for vimentin. A more intense expression of pancytokeratin was clearly evident. None of the cells expressed calretinin antigen.

Histological and immunohistochemical findings were consistent with the diagnosis of a papillary epithelioid malignant mesothelioma. Coexpression of vimentin and pancytokeratin, with a higher expression of the latter, confirmed the diagnosis. The negative expression of calretinin conflict with the diagnosis of mesothelioma; however, calretinin has proved negative in feline mesotheliomas (Bacci et al., 2006) and its reactivity not yet investigated in lions.

The research of inorganic fibers (particles with length-to-width ratio >3) in tumour and lung tissue was carried out according to Belluso et al. (2006). After chemical digestion of the organic matrix and the subsequent filtration of the inorganic suspension through a cellulose filter, 
every sample was investigated by Scanning Electron Microscope with annexed Energy Dispersive Spectrometer (SEM-EDS).

To investigate on possible presence of asbestos in shelter material, several samples were collected; fibers observed by light microscopy were drawn, suitably prepared and examined by X-ray diffraction (XRD) with the powder method, using a Siemens D5000 diffractometer equipped with $\mathrm{Cu}$-Ka radiation.

Asbestos fibers and asbestos bodies were not detected respectively by light microscopy and SEM-EDS investigations in tumour and lung tissues. To our best knowledge, no asbestos fibers have been found in other cases of (large) feline mesotheliomas. Possible reasons for the absence of asbestos fibers in an asbestos-related mesothelioma are related to a ready clearing of short fibers and asbestos dust (Dodson et al., 2003). On the contrary, chrysotile asbestos were identified by XRD in samples from shelter material.

Malignant mesothelioma is a rare type of tumour of the serosal surfaces (pleura, pericardium, peritoneum, and tunica vaginalis of the testicles) whose only recognized cause is exposure to asbestos, although in most cases the etiology of the tumour is unidentified. Experimental evidence suggests that asbestos fibers pose a risk for mesothelioma (Gibbs and Berry, 2008), and that heavy and prolonged exposure to chrysotile can produce lung cancer (Bernstein and Hoskins, 2006). Studies performed in rats also supported that chrysotile fibers were contributory to the induction of malignant mesothelioma (Dodson et al., 2003).

Since she was born, the lion was housed during the night in a cage covered by boards made of cement and asbestos fibers, therefore a link may be easily hypothesized between the inhalation of asbestos fibers and the lesion as already described in humans (Ismail-Khan et al., 2006; Tsao et al., 2009).

Environmental exposure to asbestos may therefore pose a risk for both animals housed in contaminated settings and for zoo keepers, underscoring the importance of work practices that decrease exposure to these contaminants, and suggesting the adoption of decontamination measures. 


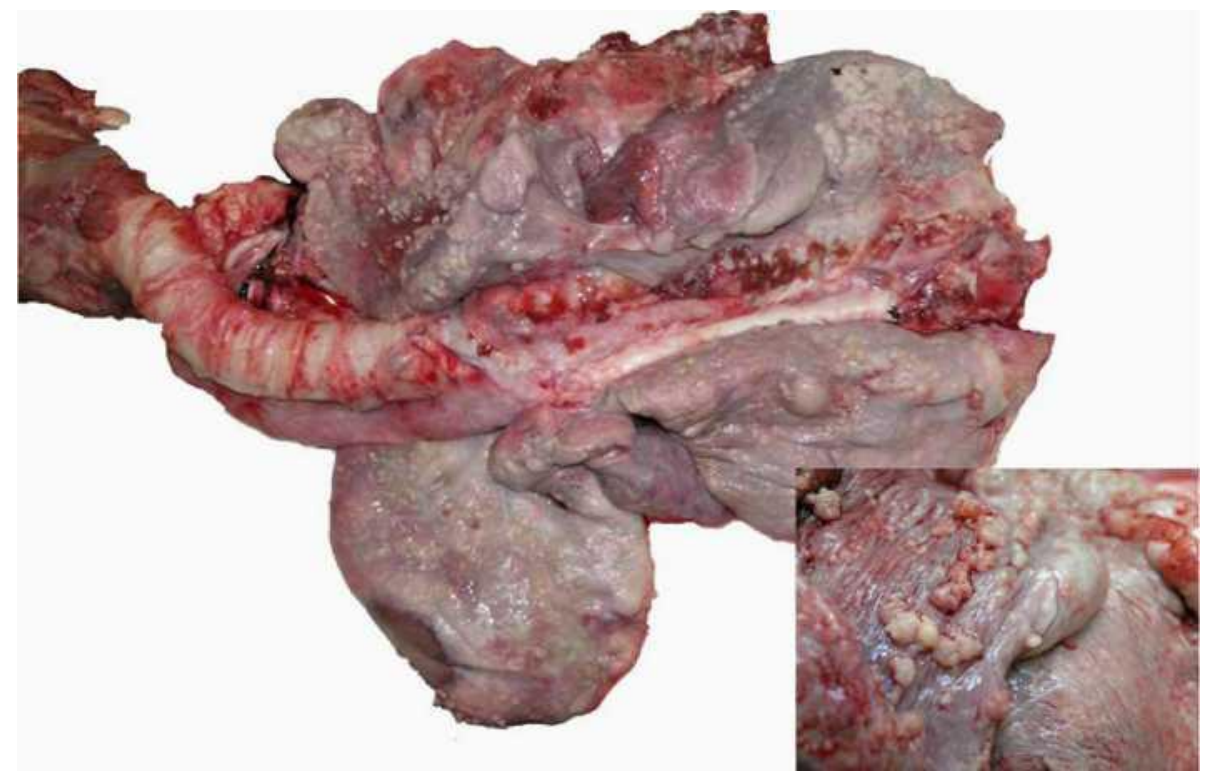

Fig. 1. Lion, lungs: multiple confluent white firm nodules. Insert: nodules on the pleural surface of the lungs.

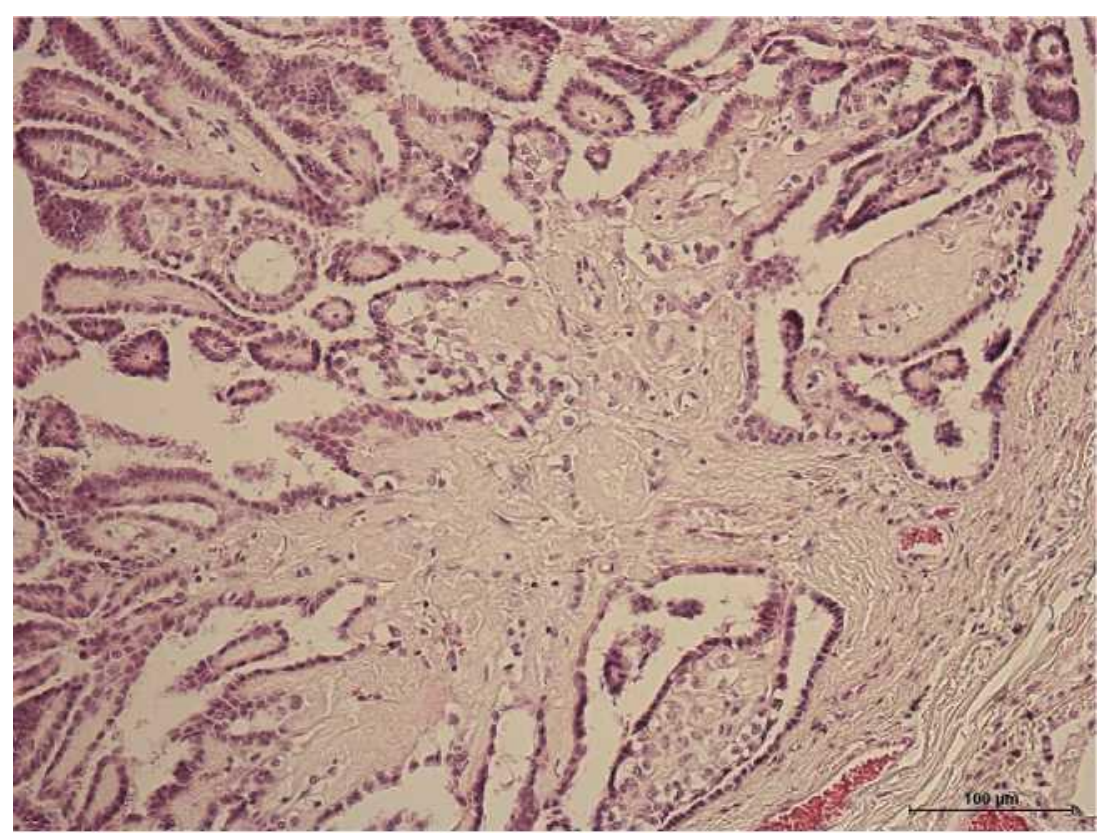

Fig. 2. Lion, microscopical image of a nodule: epithelial malignant mesothelioma: proliferations of papillary structures lined by cuboidal basophilic mesothelial cells with large, oval nuclei and abundant granular eosinophilic cytoplasm (HE). 


\section{References}

- Attanoos, R.L., Dojcinov, S.D., Webb, R., Gibbs, A.R., 2000. Anti-mesothelial markers in sarcomatoid mesothelioma and other spindle cell neoplasms. Histopathology 37, 224-231.

- Bacci, B., Morandi, F., De Meo, M., Marcato, P.S., 2006. Ten cases of feline mesothelioma: an immunohistochemical and ultrastructural study. Journal of Comparative Pathology 134, 347-354.

- Belluso, E., Bellis, D., Fornero, E., Capella, S., Ferraris, G., Coverlizza, S., 2006. Assessment of inorganic fibres burden in biological samples by SEM-EDS. Microchimica Acta 155, 95-100.

- Bernstein, D.M., Hoskins, J.A., 2006. The health eVects of chrysotile: current perspective based upon recent data. Regulatory Toxicology and Pharmacology 45, 252-264.

- Cunningham, A.A., Dhillon, A.P., 1998. Pleural malignant mesothelioma in a captive clouded leopard (Neofelis nebulosa nebulosa). Veterinary Record 143, 22-24.

- Dodson, R.F., Atkinson, M.A., Levin, J.L., 2003. Asbestos fiber length as related to potential pathogenicity: a critical review. American Journal of Industrial Medicine 44, 291-297.

- Gibbs, G.W., Berry, G., 2008. Mesothelioma and asbestos. Regulatory Toxicology and Pharmacology 52, S223-S231.

- Ismail-Khan, R., Robinson, L.A., Williams Jr., C.C., Garrett, C.R., Bepler, G., Simon, G.R., 2006. Malignant pleural mesothelioma: a comprehensive review. Cancer Control 13, 255-263.

- McCaughey, W.T.E., Kannerstein, M., Churg, J., 1983. Tumors and pseudotumors of the serous membranes. In: Atlas of Tumor Pathology, 2nd Series, Fascicle 20. Armed Forces Institute of Pathology, Washington DC, pp. 1-124.

- Mutsaers, S.E., 2004. The mesothelial cell. International Journal of Biochemistry and Cell Biology 36, 9-16.

- Nashiruddallah, N., Chakraborty, A., 2003. Spontaneous neoplasms in captive wild carnivores of the Assam state zoo. Indian Journal of Veterinary Pathology 27, 39-41.

- Rao, A.T., Acharjyo, L.N., 1994. Pleural mesothelioma in a tigress. Indian Journal of Veterinary Pathology 18,174-175.

- Shin, N.S., Kwon, S.W., Kim, D.Y., Kweon, O.K., Seo, I.B., Kim, J.H., 1998. Metastatic malignant mesothelioma in a tiger (Panthera tigris). Journal of Zoo and Wildlife Medicine 29, 81-83.

- Stewart, H.L., 1966. Pulmonary cancer and adenomatosis in captive wild mammals and birds from the Philadelphia zoo. Journal of the National Cancer Institute 36, 117-138.

- Tsao, A.S., Wistuba, I., Roth, J.A., Kindler, H.L., 2009. Malignant pleural mesothelioma. Journal of Clinical Oncology 27, 2081-2090.

- Wiedner, E.B., Isaza, R., Lindsay, W.A., Case, A.L., Decker, J., Roberts, J., 2008. Pericardial mesothelioma in a Bengal tiger (Panthera tigris). Journal of Zoo and Wildlife Medicine 39, 121-123. 